\title{
The effect of flavoured and non-flavoured tobacco on subjective experience, topography and toxicant exposure among waterpipe smokers
}

\author{
Ziyad Ben Taleb 다, ${ }^{1}$ Mayra Vargas, ${ }^{2}$ Mohammad Ebrahimi Kalan 다, ${ }^{2}$ \\ Alison Breland, ${ }^{3}$ Thomas Eissenberg, ${ }^{4}$ David Brown, ${ }^{5}$ Wasim Maziak ${ }^{6}$
}

\begin{abstract}
- Additional material is published online only. To view please visit the journal online (http://dx.doi.org/10.1136/ tobaccocontrol-2019-054972).

${ }^{1}$ Kinesiology, University of Texas at Arlington, Arlington, Texas, USA

2Epidemiology, Florida International University, Miami, Florida, USA

${ }^{3}$ Psychology, Virginia Commonwealth University, Richmond, Virginia, USA ${ }^{4}$ Psychology and Inst. for Drug/Alc. Studies, Virginia Commonwealth University, Richmond, Virginia, USA

${ }^{5}$ Division of Family and College of Medicine Community Medicine, Florida International University, Miami, Florida, USA ${ }^{6}$ Epidemiology, Florida International University, Miami Florida, USA
\end{abstract}

Correspondence to Dr Wasim Maziak, College of Public Health, Florida International University, Miami, FL 33174, USA: wmaziak@fiu.edu

Received 22 March 2019 Revised 26 August 2019 Accepted 30 August 2019 Published Online First 25 November 2019

\section{ABSTRACT}

Introduction Flavoured waterpipe (WP) tobacco is a major factor in the resurgence of WP smoking and a main attractant of WP use among youth. Yet, evidence of the effects of limiting flavour on WP smoker's experiences and exposures is limited. This study examined the impact of flavour manipulation on WP smokers' toxicant exposure and smoking experiences. Method A total of 144 WP smokers attended two, $45 \mathrm{~min}$ ad libitum smoking sessions (flavoured vs non-flavoured tobacco) in a crossover design study. Participants completed a battery of questions assessing subjective smoking experiences. Exhaled carbon monoxide (eCO) and plasma nicotine concentrations were measured before and after the smoking sessions. Puff topography was recorded throughout the smoking sessions.

Results Compared with the non-flavoured WP tobacco, participants reported enhanced subjective smoking measures of satisfaction and enjoyment following smoking flavoured WP tobacco (ps <0.05). Although participants spent a longer time smoking flavoured tobacco, they took on average larger puffs while smoking the non-flavoured tobacco (ps <0.05). Greater levels of eCO were recorded following the non-flavoured tobacco session $(p<0.05)$ compared with flavoured tobacco. No significant differences were observed in plasma nicotine concentrations between the two tobacco conditions. WP harm perception was higher among participants after smoking non-flavoured WP tobacco compared with their preferred flavour $(p<0.05)$.

Conclusion Smoking the flavoured tobacco product was associated with enhanced subjective experiences compared with the non-flavoured, suggesting a potential role for flavour regulation in reducing WP use. Mixed results were observed for toxicants exposure in relation to smoking flavoured compared with non-flavoured products suggesting the need for a more comprehensive assessment of the effects of other tobacco constituents and additives on toxicant exposure in WP smokers.

\section{INTRODUCTION}

During the last two decades, waterpipe (WP) tobacco smoking has gained popularity both in the USA and globally. ${ }^{12}$ Data from the 2014 Population Assessment of Tobacco and Health estimated that $10.7 \%$ of young adults between the ages of 18 and 24 currently (last 30 days) smoke WP in the USA. ${ }^{3}$ Additionally, recent data from the 2018 National College Health Assessment showed that $14.7 \%$ of college students have ever used WP. ${ }^{4}$ A growing body of evidence suggests that WP use can lead to nicotine dependence and many of the known smoking-related illnesses such as cancer, cardiovascular disease and a variety of respiratory diseases. ${ }^{56}$ Additionally, by providing a gateway to cigarette smoking, WP smoking also threatens to undermine success in curbing cigarette smoking in the USA. ${ }^{7}$

Several factors may have contributed to the surge in popularity of WP smoking, including the flavouring of WP tobacco, perception of reducedharm and the promotion and marketing of WP tobacco products and venues on the internet and social media. ${ }^{1} 89$ Flavoured tobacco products are widely available, and are commonly used by youths. ${ }^{10}$ A national study examining flavoured tobacco product use among youth in 2013-2014 showed that the majority of youth tobacco users $(81 \%)$ reported that the first tobacco they ever used was flavoured, with WP having the highest rate of flavoured tobacco use (89\%). ${ }^{10}$ Flavoured WP tobacco is usually manufactured by mixing tobacco with honey (molasses), glycerin and fruit-based additives and flavours. ${ }^{11} 12$

While some local jurisdiction in the USA (eg, the city of San Francisco) do ban retail sales of flavoured WP tobacco, a similar regulation on the national level does not exist. In 2016, the Food and Drug Administration (FDA) extended its regulatory authority over tobacco products to include WP. ${ }^{13}$ This development creates an opportunity to provide evidence to inform the FDA on the potential of flavour regulation to curtail WP use among youth in the USA. Yet, empirical evidence of the effects of eliminating flavours on WP smokers' experiences and behaviour is limited. Two studies to date have investigated the effect of flavour variations on young WP smokers' (18-38 years old) experiences and exposures. The first showed that even a minor manipulation of flavour preference has a significant effect on smoking subjective experiences, and suggested the need to study the impact of completely eliminating flavour on the overall smoking experience and toxicant exposure. ${ }^{14}$ As a proof of concept of the effect of eliminating flavour on WP smokers' experience, we conducted a pilot study involving 32 WP smokers, who were compared when smoking their preferred flavour versus non-flavoured tobacco. ${ }^{15}$ Our preliminary findings indicated that compared with nonflavoured tobacco, study participants reported an enhanced smoking experience while using flavoured WP tobacco with no changes in puffing 
behaviour. The current study expands this work by utilising a larger sample size $(n=144)$ and assessing additional outcomes including nicotine withdrawal symptoms and urges to smoke. Accordingly, this study aims at comparing the effect of limiting flavour on (1) puffing behaviour, (2) exposure to nicotine and carbon monoxide, (3) subjective measures and (4) nicotine withdrawal symptoms and urges to smoke. We hypothesised that in comparison with flavoured WP tobacco, smoking non-flavoured tobacco will be associated with a reduced satisfactory smoking experience, less intense puffing and shorter smoking sessions resulting in reduced exposure to nicotine and carbon monoxide.

\section{METHODS}

\section{Participants}

A total of 144 participants were recruited from the metropolitan area surrounding Miami, Florida by placing flyers around WP venues, word of mouth and internet advertisements. Participants were healthy and smoked flavoured WP at least once/month in the last 6 months. Participants were between the ages of 18 and 30 years and provided informed consent for study participation. Exclusion criteria included: (1) self-reported history of health problems or psychiatric diseases; (2) regular use of medications; (3) self-reported current use of $>5$ cigarettes/month or other tobacco/nicotine products; and (4) currently pregnant or breast feeding.

\section{Procedure}

Eligible participants completed two counterbalanced 2-hour sessions that differed by tobacco condition (preferred flavour vs non-flavoured WP tobacco) separated by a 48-hour washout period to avoid carryover effect. Participants who had a specific preference were asked to bring their own preferred flavour/ brand. Otherwise, participants were offered a variety of flavours at the lab to choose from. Prior to smoking, the WP head was filled with $15 \mathrm{~g}$ of session-specific tobacco product and covered with perforated foil. ${ }^{16}$ Two pieces of quick-lighting charcoal were lit by study staff and placed on top of the foil. During each session, participants were seated in a comfortable recliner chair and were permitted to watch a movie of their choice. Participants were instructed to use WP ad libitum for up to $45 \mathrm{~min}$, while puff topography was measured. Subjective effects were assessed, blood was sampled and exhaled carbon monoxide (eCO) concentration was measured before and after the 45-min WP use session. ${ }^{17}$

\section{Measures}

Demographics

Participants completed questionnaires assessing age, gender, ethnicity and student status.

\section{WP smoking frequency and patterns}

Participants self-reported their WP smoking frequency by responding to the following question: 'On average how many hookahs (heads/bowels) you usually smoke per month?'. ${ }^{18}$ Participants self-reported their WP smoking patterns by responding to the following questions: 'At what age did you smoke hookah for the first time in your life?', 'What is the average time you usually spend during a hookah smoking session?', 'Do you usually share the same hookah with others?', 'Where do you usually smoke hookah?'. ${ }^{18}$ To assess flavour preference, participants were asked to 'specify the type of tobacco flavour you usually smoke'.

\section{Other tobacco product use}

Participants self-reported use of any tobacco products ( $\leq 5$ times/ month) by answering the following question 'Do you regularly use any of the following tobacco/nicotine products?': cigarettes, electronic cigarettes, cigar, Cigarillos/Little cigars, smokeless tobacco, other and none.

\section{WP puff topography}

Puff topography was assessed using a validated instrument ${ }^{15}$ with software that converted pressure signals to air flow $(\mathrm{mL} / \mathrm{s})$ data, producing measures of total time spent smoking, cumulative puffing time, puff duration, interpuff interval, number of puffs, total volume inhaled, average puff volume and maximum puff volume.

\section{Plasma nicotine}

Blood samples were centrifuged and plasma stored at $-80^{\circ} \mathrm{C}$, to be analysed later for nicotine concentration. The analysis was conducted using gas chromatography-mass spectrometry (GCMS). ${ }^{19}$ The assay's limit of quantitation (LOQ) was $1.0 \mathrm{ng} / \mathrm{mL}$. LOQ is defined as the lowest concentration of nicotine that can be precisely determined using the GC-MS method. For nicotine analysis in our study, the LOQ was $1.0 \mathrm{ng} / \mathrm{mL}$. Accordingly, any sample analysis yielding less than the LOQ was replaced with $1.0 \mathrm{ng} / \mathrm{mL}$. This approach is more conservative than assuming values below the LOQ were zero. Additional analyses were conducted to measure nicotine content in flavoured and nonflavoured tobacco products using GC-MS.

\section{Exhaled carbon monoxide}

Measurements of eCO were recorded before and 5 min after WP use via BreathCO monitor (Vitalograph, Lenexa, Kansas, USA).

\section{Subjective measures \\ The WP Evaluation Scale}

The WP Evaluation Scale (WES) is an 11-item questionnaire that was adapted from a scale used for cigarettes. ${ }^{20} 21$ This scale assesses participants' perception of the smoked WP. For example, to assess satisfaction, participants were asked to evaluate the hookah they just smoked by answering the following question: 'Was it satisfying?'. Each item was rated on a 7-point Likert scale ('not at all' to 'extremely'). WES was administered post-WP smoking.

\section{The Duke Sensory Questionnaire}

The Duke Sensory Questionnaire (DSQ) has nine items that assess participants' sensory experience of the inhaled product. For example, participants were asked to evaluate the WP they just smoked by answering the following question: 'How much did you like the puffs?' All questions were rated on a 7-point Likert scale (not at all to extremely). ${ }^{22}$ DSQ was administered post-WP smoking.

\section{Harm perception}

Harm perception was assessed using a 3-item scale. ${ }^{23}$ The direct measure was; 'Compared with your usual flavoured brand, this WP is...' with answers on a 7-point scale ranging from 'a lot less harmful' to 'a lot more harmful'. To measure perceptions of WP's relative risk compared with cigarettes, we asked two questions: (1) 'How harmful is the WP to health?' (2) 'How harmful is smoking cigarettes for health?'. The answers to both were rated on a 7 -point scale ranging from 1 (not at all harmful) to 7 
(extremely harmful). Harm perception was measured post-WP smoking.

\section{Minnesota Nicotine Withdrawal Scale}

Minnesota Nicotine Withdrawal Scale (MNWS) consists of 11 items: (1) urges to smoke, (2) irritability/frustration/anger, (3) anxious, (4) difficulty concentrating, (5) restlessness, (6) hunger, (7) impatient, (8) craving nicotine, (9) drowsiness, (10) depression/feeling blue and (11) desire for sweets. ${ }^{24}$ Items were presented as Visual Analogue Scales with the item centred above a horizontal line. Participants clicked a mouse to mark anywhere along the horizontal line, where the score is the distance between the mark and the left anchor, expressed as a percentage of total line length. The MNWS was measured pre-WP and post-WP smoking.

\section{Questionnaire of Smoking Urges-Brief}

Questionnaire of Smoking Urges-Brief (QSU) consists of 10 items that were adapted to WP smoking and rated on a 7-point Likert scale ranging from 0 (strongly disagree) to 6 (strongly agree). ${ }^{25}$ Items are: (1) I have a desire to smoke now; (2) nothing better than smoking now; (3) if it were possible, I probably would smoke now; (4) I could control things better now if I could smoke; (5) all I want now is to smoke; (6) I have an urge for a WP; (7) a WP would taste good now; (8) I would do almost anything for a WP now; (9) smoking would make me less depressed; and (10) I am going to smoke WP as soon as possible. The 10 items form two factors: factor I (intention to smoke) and factor II (anticipation of relief from withdrawal). The QSU was assessed pre-WP and post-WP smoking. ${ }^{26}$

During each flavoured tobacco smoking session, the brand and flavour of the tobacco used, were recorded. In addition, following completion of all smoking sessions, participants were asked to evaluate the amount of smoke produced after each session by responding to this question 'Which waterpipe tobacco produced the greater amount of smoke during your smoking session' with the following answer options (1) flavoured tobacco, (2) non-flavoured tobacco and (3) no difference.

\section{Data preparation and analysis}

Characteristics of the study sample were summarised with means and SDs or proportions. Means were calculated for all subjective measures and compared by tobacco condition using two-tailed paired samples t-tests. Similar to previous studies, ${ }^{15} 27$ plasma nicotine concentration values below LOQ were replaced with the LOQ $(1 \mathrm{ng} / \mathrm{mL})$, which is more conservative than assuming values below the LOQ were zero. Consumed tobacco for each condition was calculated by subtracting the remaining tobacco weight after each smoking session from the baseline tobacco weight $(15 \mathrm{~g})$. Sensitivity analysis was performed to evaluate whether results were influenced by using the complete dataset $(n=144)$ with our pilot study data included vs excluding data from our pilot study $(n=112)$. This analysis revealed that retaining data from the pilot study did not affect the direction of results, therefore we utilised the complete dataset for final analyses $(n=144)$ (supplementary tables 1 and 2). Data for subjective measures were missing for one participant. Data for plasma nicotine samples were missing for 13 participants due to the inability to draw blood. The mean of the data from the other 131 participants at that time point was substituted and, when the data were analysed with and without these 13 participants, the results were unchanged. Therefore, all results for plasma nicotine concentration are reported with $n=131$. In order to

\begin{tabular}{|c|c|}
\hline Variables & Overall sample \\
\hline \multicolumn{2}{|l|}{ Gender (\%) } \\
\hline Female & 41 \\
\hline Male & 59 \\
\hline \multicolumn{2}{|l|}{ Race (\%) } \\
\hline White & 67.4 \\
\hline Non-white & 32.6 \\
\hline Hispanic (\%) & 58.3 \\
\hline Age (in years)* & $21.8(2.9)$ \\
\hline Age of first smoking of waterpipe* & $17.7(2.4)$ \\
\hline Student status (\%) & 67.4 \\
\hline Waterpipe uses/month* & $6.1(9.2)$ \\
\hline Screening eCO* & $2(1.3)$ \\
\hline \multicolumn{2}{|c|}{ Average time spent smoking waterpipe (\%) } \\
\hline Less than $30 \mathrm{~min}$ & 9 \\
\hline $30-60 \mathrm{~min}$ & 60.4 \\
\hline More than $60 \mathrm{~min}$ & 30.6 \\
\hline \multicolumn{2}{|l|}{ Tobacco use $(\%) \dagger$} \\
\hline Cigarettes & 37.5 \\
\hline E-cigarettes & 1.3 \\
\hline Cigars & 0.6 \\
\hline Sharing waterpipe with others (\%) & 91.6 \\
\hline \multicolumn{2}{|l|}{ Location of waterpipe smoking (\%) } \\
\hline At home & 22.2 \\
\hline At friends' place & 27.1 \\
\hline At a public place & 50.7 \\
\hline \multicolumn{2}{|l|}{ Preferred flavours (\%) } \\
\hline Mixed fruits & 33.5 \\
\hline Apple & 31.9 \\
\hline Mint & 22.2 \\
\hline Grape & 10.4 \\
\hline Other & 2 \\
\hline
\end{tabular}

${ }^{*}$ Data presented as mean (SD).

tTobacco use of $\leq 5$ times/month.

$\ddagger$ ther includes mango, watermelon and blueberry.

eCO, exhaled carbon monoxide.

compare the effects of WP tobacco condition on nicotine withdrawal symptoms and plasma nicotine and eCO concentration, data were entered into a repeated measures ANOVA with two within-subject factors: time (pre-WP and post-WP) and WP tobacco condition (flavoured and non-flavoured). Huynh-Feldt corrections were used to adjust for violations of the sphericity assumption. ${ }^{28}$ Pearson's correlation coefficients were calculated to assess the strength of the relationship between nicotine boost (change in plasma nicotine concentration pre-post) and nicotine withdrawal symptoms. Significance was set at $p<0.05$. All analyses were performed in IBM SPSS V.21. ${ }^{29}$

\section{RESULTS}

Table 1 shows a detailed description of study participants' baseline characteristics. Study participants had a mean age of 21.8 $(\mathrm{SD}=2.9)$ years and the majority were men $(n=85 ; 59 \%)$. The mean age for starting WP smoking among participants was $17.7(\mathrm{SD}=2.4)$ years. For participants' preferred brand, the most commonly used tobacco bands were Al Fakher $(n=134)$, followed by Starbuzz $(n=9)$, and Haze $(n=1)$. For the nonflavoured condition, all participants smoked Zaghloul Nakhla, a non-flavoured WP tobacco preparation. There was a significant difference in the amount of consumed tobacco following the 
Table 2 Waterpipe smoking topography measures by flavour condition conditions $(n=143)$ *

\begin{tabular}{|c|c|c|c|c|c|}
\hline \multirow{2}{*}{$\begin{array}{l}\text { Topography } \\
\text { parameters }\end{array}$} & \multicolumn{2}{|c|}{ Flavoured tobacco } & \multicolumn{2}{|c|}{$\begin{array}{l}\text { Non-flavoured } \\
\text { tobacco }\end{array}$} & \multirow[b]{2}{*}{$P$ value } \\
\hline & Mean & SD & Mean & SD & \\
\hline Smoking time, min & $42: 23$ & $7: 52$ & $40: 32$ & 9:22 & 0.01 \\
\hline $\begin{array}{l}\text { Cumulative puffing } \\
\text { time, min }\end{array}$ & $5: 37$ & 3:36 & $4: 48$ & $2: 56$ & 0.003 \\
\hline Puff duration, s & 3.4 & 1.5 & 3.2 & 1.4 & 0.32 \\
\hline Interpuff interval, s & 27 & 17.4 & 29.7 & 19.6 & 0.06 \\
\hline Number of puffs & 109.1 & 76.7 & 101 & 77.3 & 0.09 \\
\hline Total volume, L & 66.8 & 48.3 & 66.7 & 45.6 & 0.97 \\
\hline Puff volume, L & 0.68 & 0.41 & 0.79 & 0.48 & 0.01 \\
\hline Maximum puff volume, L & 1.64 & 0.79 & 2.05 & 1 & $<0.001$ \\
\hline
\end{tabular}

*One participant was missing data for topography.

smoking session with a greater amount of non-flavoured tobacco consumed $(5.3 \mathrm{~g})$ compared with flavoured $(4 \mathrm{~g})(\mathrm{p}<0.05)$. Nicotine content analysis of tobacco used in both conditions revealed that on average, every $1 \mathrm{~g}$ of non-flavoured tobacco has $0.45 \mathrm{mg}$ of nicotine, while every $1 \mathrm{~g}$ of flavoured tobacco has $0.22 \mathrm{mg}$ of nicotine.

\section{WP smoking topography}

Significant differences were observed between the two conditions for the following measures: smoking time, puffing time, puff volume and maximum puff volume (table 2). Longer mean smoking and longer mean cumulative puffing time were observed for the flavoured tobacco smoking session compared with nonflavoured (42:23 vs $40.32 \mathrm{~min}$ and $5: 37$ vs $4: 48 \mathrm{~min}$, respectively; $\mathrm{p}<0.05$ ). However, during the non-flavoured tobacco smoking session, greater puff volume and greater maximum puff volume were observed compared with flavoured tobacco $(0.79$ vs $0.68 \mathrm{~L}$ and 2.05 vs $1.64 \mathrm{~L}$, respectively; $\mathrm{p}<0.01)$.

\section{Plasma nicotine}

There was no significant time by condition interaction for mean plasma nicotine concentration $(\mathrm{F}<1, \mathrm{p}>0.05)$ demonstrating that changes in plasma nicotine concentration across time did not depend on the tobacco flavour condition. Mean pre-WP plasma nicotine concentration for the flavoured tobacco condition was $1 \mathrm{ng} / \mathrm{mL}(\mathrm{SEM}=0.06)$ and increased to $8.5 \mathrm{ng} / \mathrm{mL}(\mathrm{SEM}=0.7)$ post-WP resulting in a nicotine boost of $7.5 \mathrm{ng} / \mathrm{mL}(\mathrm{SEM}=0.7)$. For the non-flavoured tobacco condition, mean pre-WP plasma nicotine concentration was $1 \mathrm{ng} / \mathrm{mL}(\mathrm{SEM}=0.05)$ and increased to $8.4(\mathrm{SEM}=0.8)$ post-WP resulting in a nicotine boost of $7.4 \mathrm{ng} / \mathrm{mL}(\mathrm{SEM}=0.6)$. Average plasma nicotine levels at postsmoking time points were not significantly different between flavoured and non-flavoured tobacco conditions ( $p>0.05$; see supplementary figure).

\section{Exhaled carbon monoxide}

A significant time by condition interaction was observed for eCO level $(\mathrm{F}(1,142)=5.3, \mathrm{p}<0.05)$ demonstrating that changes in eCO level across time depended on tobacco condition. Mean eCO level for the flavoured condition increased from $1.8 \mathrm{ppm}(\mathrm{SEM}=0.1)$ pre-WP to $22.8 \mathrm{ppm}(\mathrm{SEM}=2.1)$ post-WP with an overall change of $21 \mathrm{ppm}(\mathrm{SEM}=2)$. For the nonflavoured condition, the mean eCO level increased from $2 \mathrm{ppm}$ $(\mathrm{SEM}=0.1)$ pre-WP to $27.7 \mathrm{ppm}(\mathrm{SEM}=1.9)$ post-WP with an overall change of $25.7 \mathrm{ppm}(\mathrm{SEM}=1.9)$. As figure 1 shows, there

\section{Flavored - $\boldsymbol{m}$. Non-flavored}

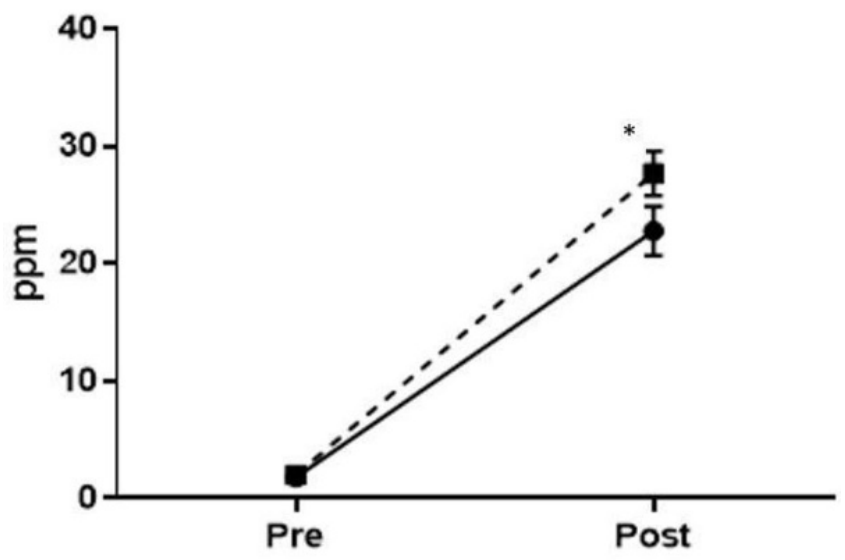

$\dagger$ One participant was missing data for $\mathrm{eCO}$ * indicates significant differences.

Figure 1 Means $( \pm S E M)$ for exhaled carbon monoxide levels pre/postWP by flavour condition $(n=143)$. $†$ WP, eCO, exhaled carbon dioxide; WP, waterpipe.

was a higher boost in $\mathrm{eCO}$ for non-flavoured tobacco compared with flavoured tobacco $(p>0.05)$.

\section{Subjective measures}

Participants' assessment of each tobacco product's ability to generate smoke showed that $69.8 \%$ of participants believed that flavoured tobacco produced more smoke, while $20.9 \%$ believed that non-flavoured tobacco produced more smoke and 9.3\% believed there was no difference $(\mathrm{p}<0.05)$.

Figures 2 and 3 depict mean ratings for WES and DSQ, respectively. For the WES, significant differences were observed between the two tobacco conditions for all indices except for 'did it reduce your craving?'. For all items, values were greater after smoking flavoured tobacco compared with non-flavoured tobacco $(p<0.01)$, except for 'Did it make you feel nauseous?' which was greater after smoking the non-flavoured tobacco $(\mathrm{p}<0.05)$. For the DSQ, significant differences were observed between the two tobacco conditions for the following indices: 'How much did you like the puffs?', 'How satisfying were the puffs?', 'How similar to your own brand/flavour were the puffs?', 'Rate the strength of the puffs on the windpipe' and 'How high in nicotine were the puffs?'. For each of these items, scores were greater after smoking flavoured tobacco $(p<0.01)$, except for 'How high in nicotine were the puffs?' which was greater after smoking non-flavoured tobacco $(\mathrm{p}<0.05)$.

For both tobacco conditions, there were no significant differences in harm perception among participants towards cigarette, and WP smoking in general $(\mathrm{p}>0.05)$. However, harm perception scores were significantly higher for non-flavoured tobacco when compared with the participant's usual flavoured brand $(\mathrm{p}<0.05)$ (figure 4$)$.

Table 3 shows detailed results for MNWS. Across all items, there was no significant interaction between condition and time, demonstrating that changes in MNWS across time did not depend on the tobacco flavour condition. There was a significant effect for time across the following MNWS items: 'Urges to smoke a waterpipe', 'Difficulty concentrating', 'Hunger', 'Craving a waterpipe/Nicotine' and 'Drowsiness'. Mean scores 


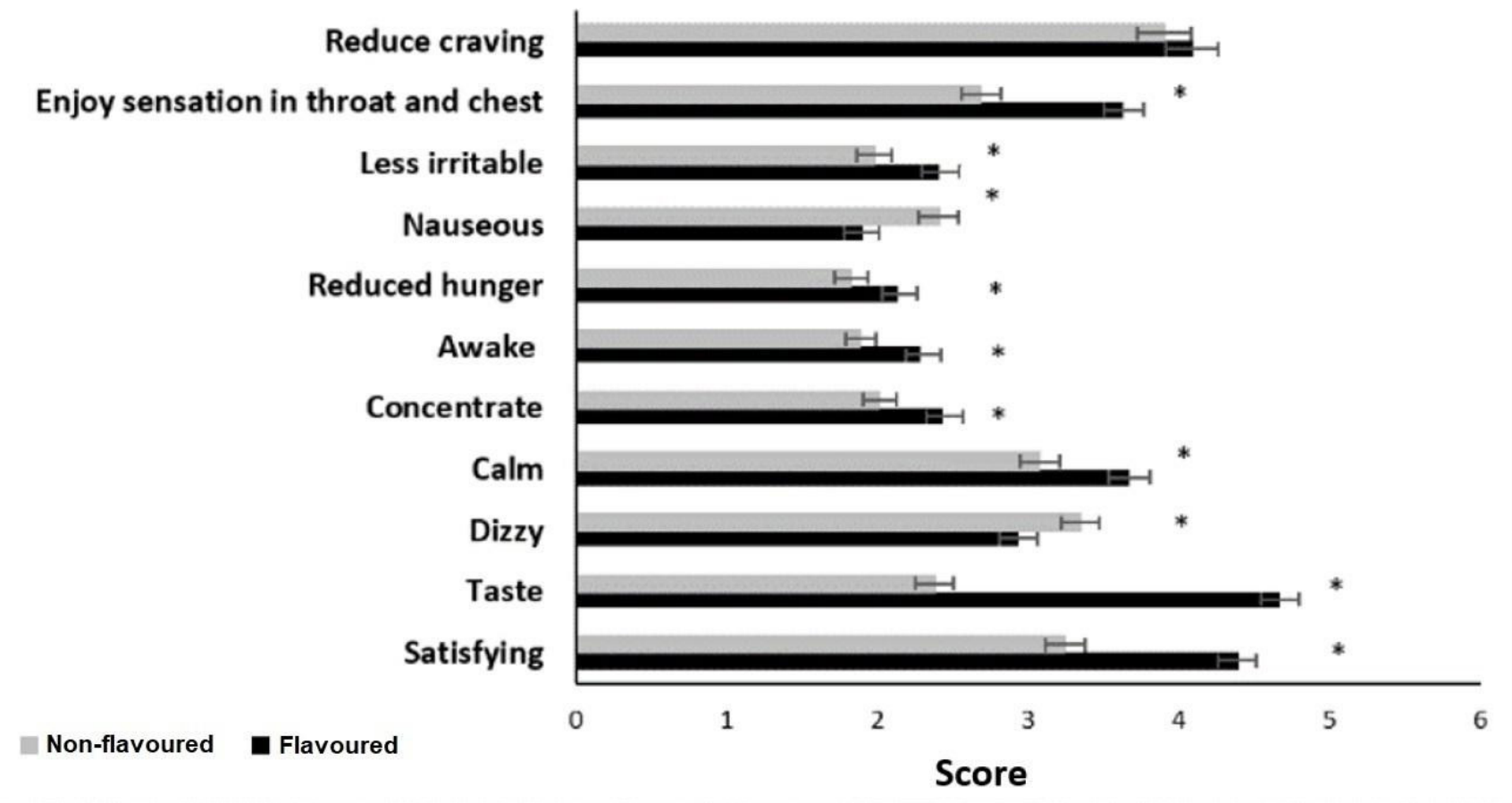

† One participant was missing data for the flavoured tobacco sessions. * indicates significant differences.

Figure 2 Means $( \pm$ SEM) for post-WP subjective responses for Waterpipe Evaluation Scale by flavour condition $(n=143) . \dagger$ WP, waterpipe.

for all the above-mentioned items reduced significantly from presmoking to post-WP except for 'hunger' which increased from pre-smoking to post-WP. For factors I and II of the QSU-Brief (table 3), there was no significant interaction between condition and time, demonstrating that changes in factors I and II across time did not depend on the tobacco condition. There was a significant effect of time observed for both factors, in which scores were reduced significantly from pre-WP to post-WP.
Following the flavoured tobacco smoking session, plasma nicotine boost was correlated with pre-WP urges to smoke $(\mathrm{r}=0.28, \mathrm{p} \leq 0.05)$, craving $(\mathrm{r}=0.18, \mathrm{p} \leq 0.05)$ and with QSU factor I $(r=0.29, p \leq 0.05)$ and factor II $(r=0.20, p \leq 0.05)$. Similarly, following the non-flavoured smoking session, plasma nicotine boost was correlated with pre-WP urges to smoke $(r=0.26$, $\mathrm{p} \leq 0.05)$, craving $(\mathrm{r}=0.20, \mathrm{p} \leq 0.05)$ and with QSU factor I $(\mathrm{r}=0.20, \mathrm{p} \leq 0.05)$ and factor II $(\mathrm{r}=0.19, \mathrm{p} \leq 0.05)$.

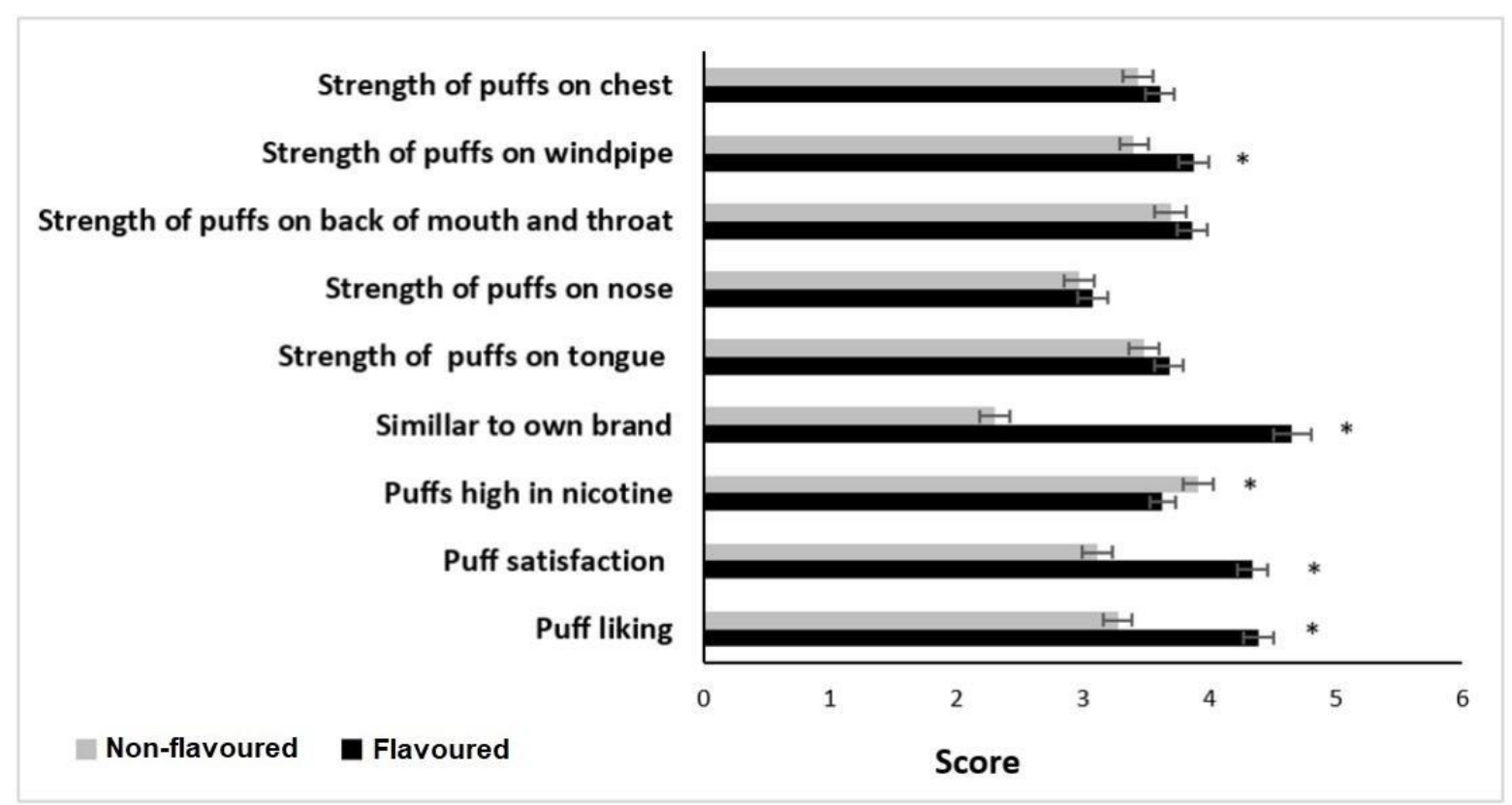

† One participant was missing data for the flavoured tobacco sessions. * indicates significant differences.

Figure 3 Means $( \pm$ SEM) for post-WP subjective responses for Duke Sensory Questionnaire by flavour condition $(n=143)$. $†$ WP, waterpipe. 


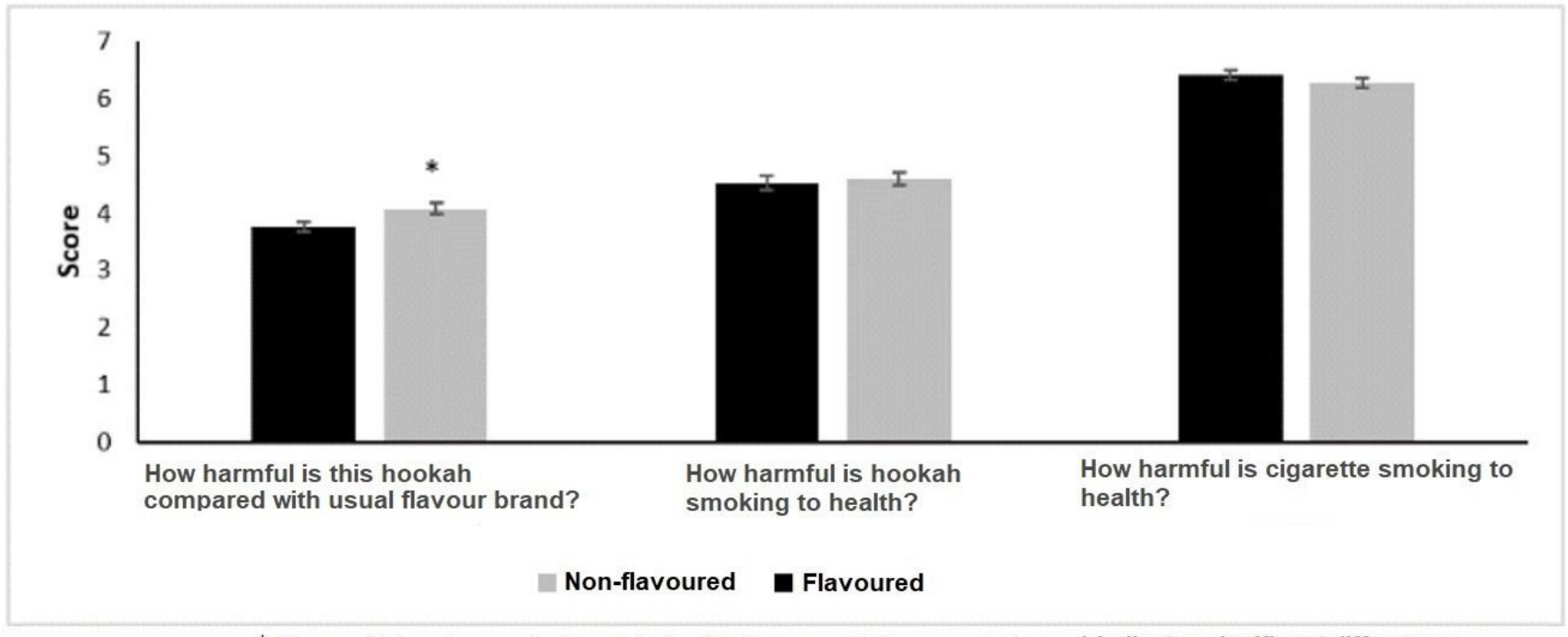

† One participant was missing data for the flavoured tobacco sessions. * indicates significant differences.

Figure 4 Means $( \pm$ SEM) for post-WP harm perception responses by flavour condition $(n=143) . \dagger$ WP, waterpipe.

\section{DISCUSSION}

This study demonstrates the substantial effects of eliminating tobacco flavour on puffing behaviour, toxicant exposure and subjective experiences among young adult WP smokers. Following smoking flavoured tobacco, WP smokers reported an overall enhanced smoking experience with higher levels of enjoyment and satisfaction and lower harm perception. While there was no difference in plasma nicotine concentration among participants following smoking both tobacco products, greater

Table 3 ANOVA results for withdrawal symptoms/smoking urges by time (pre vs post) and condition (flavoured vs non-flavoured) ( $n=143$ )

\begin{tabular}{|c|c|c|c|c|c|c|}
\hline & \multicolumn{2}{|c|}{ Condition } & \multicolumn{2}{|l|}{ Time } & \multicolumn{2}{|c|}{ Condition $\times$ time } \\
\hline & $\mathbf{F}$ & $P$ value & $\mathbf{F}$ & $P$ value & $\mathbf{F}$ & $P$ value \\
\hline \multicolumn{7}{|c|}{ Minnesota Nicotine Withdrawal Scale } \\
\hline $\begin{array}{l}\text { Urges to smoke a } \\
\text { waterpipe }\end{array}$ & $<0.1$ & n.s & 66.4 & $<0.01$ & 0.4 & n.s \\
\hline $\begin{array}{l}\text { Irritability/ } \\
\text { frustration/anger }\end{array}$ & $<0.1$ & n.s & 1.1 & n.s & 0.1 & n.s \\
\hline Anxious & 1.2 & n.s & 2.4 & n.s & 0.4 & n.s \\
\hline $\begin{array}{l}\text { Difficulty } \\
\text { concentrating }\end{array}$ & 2.1 & n.s & 7.2 & $<0.01$ & 1.5 & n.s \\
\hline Restlessness & 1.8 & n.s & 0.2 & n.s & 0.5 & n.s \\
\hline Hunger & 4.4 & $<0.05$ & 22.5 & $<0.01$ & 0.6 & n.s \\
\hline Impatient & 2.5 & n.s & 0.4 & n.s & 0.2 & n.s \\
\hline $\begin{array}{l}\text { Craving a } \\
\text { waterpipe/ } \\
\text { nicotine }\end{array}$ & 0.3 & n.s & 37.8 & $<0.01$ & $<0.1$ & n.s \\
\hline Drowsiness & 1.8 & n.s & 40.4 & $<0.01$ & 2.7 & n.s \\
\hline $\begin{array}{l}\text { Depression/ } \\
\text { feeling blue }\end{array}$ & 1.4 & n.s & $<0.1$ & n.s & 0.4 & n.s \\
\hline Desire for sweets & 1.6 & n.s & 3.9 & n.s & 0.5 & n.s \\
\hline \multicolumn{7}{|c|}{ Questionnaire of Smoking Urges (QSU) } \\
\hline Factor $1^{*}$ & 0.4 & n.s & 148.8 & $<0.01$ & 1 & n.s \\
\hline Factor $2 \dagger$ & 1.2 & n.s & 43.2 & $<0.01$ & 0.2 & n.s \\
\hline
\end{tabular}

*Intention to smoke.

†Anticipation of relief from withdrawal.

ns, non-significant. levels of eCO were recorded among participants following smoking the non-flavoured tobacco.

In line with our pilot study ${ }^{15}$ the results show that subjective positive and negative smoking experiences were dependent on the flavour condition, where smoking flavoured WP tobacco enhanced positive experiences and reduced negative responses. For example, participants found the flavoured tobacco to be more satisfying, calming, good tasting, well-liked and experienced less dizziness and nausea compared with the nonflavoured tobacco. This is likely because flavouring and other additives in WP tobacco reduce and mask the harsh taste of raw tobacco, facilitating a more positive WP smoking experience. ${ }^{10}$ In contrast, non-flavoured tobacco has a low amount of humectant (glycerin) and molasses, which is associated with a higher burning temperature of tobacco and low production of particulate matter (PM). ${ }^{30}{ }^{31}$ Indeed, our study participants reported that non-flavoured tobacco is less efficient in generating the usual smoke cloud, for which PM is a major source. It is likely that in their attempt to produce the usual smoke, the participants were taking deeper puffs that enhanced the combustion process leading to more eCO production, and nausea associated with higher levels of exposure to $\mathrm{CO}^{31}{ }^{32}$ Our data support such a possible scenario, where the non-flavoured condition was associated with larger puff volumes and higher eCO boosts compared with the flavoured condition. These findings validate our pilot work that showed a trend towards larger puffs and greater eCO levels among participants following smoking non-flavoured tobacco. ${ }^{15}$ Accordingly, merely eliminating flavour may lead to compensating smoking behaviour, which in turn can increase exposure to some toxicants.

Another important piece of this puzzle is offered by the unexpected equal levels of nicotine exposure in the flavoured versus non-flavoured conditions, which mirrored the similarity in the level of suppression of nicotine withdrawal symptoms and urges to smoke between the two conditions. When we planned the study, we hypothesised that because the flavour condition would be more enjoyable, participants would likely get more nicotine smoking the flavoured products and accordingly greater suppression of withdrawal symptoms. However, what we are learning-and this knowledge is still unfolding-is that many 
factors likely will influence drug self-administration including degree of nicotine dependence, composition of the product itself other than flavour (eg, concentration of humectant), puffing behaviour, exposure to other toxicants, nicotine content in the product itself and nicotine yields in the mainstream smoke. These factors will influence nicotine exposure in different directions. For example, in our study, nicotine content in nonflavoured tobacco was higher than in the flavoured tobacco. On the other hand, flavoured WP tobacco has higher levels of humectant which has been shown to be associated with higher nicotine yields in WP mainstream smoke. ${ }^{30}$ It seems, however, that nicotine dependence level will likely balance out these factors so smokers will adapt their smoking to self-administer their usual dose of nicotine. This assumption is supported by our findings showing a positive correlation of urges to smoke and craving with nicotine boost regardless of tobacco condition and other factors.

While this study addresses important gaps in the literature, it has some limitations. The laboratory setting inevitably is different from the typical WP lounge vibe. However, to simulate the WP café environment, our laboratory was furnished with a reclining chair, and participants were invited to choose a movie to watch while smoking. These features made the session area more relaxing and entertaining to mimic a natural smoking experience. Additionally, in our study, participants smoked WP alone in a laboratory environment. Therefore, the results may differ outside the laboratory as WP is commonly shared with peers. ${ }^{33}$ Nevertheless, our research represents a critical step in understanding the effects of flavour and tobacco composition in shaping the overall WP smoking experience.

In this laboratory crossover design study, we were able to demonstrate that flavoured WP tobacco smoking is associated with enhanced subjective smoking experiences, and lower harm perception compared with non-flavoured WP tobacco. On the other hand, eliminating flavour was associated with taking larger puffs and greater exposure to CO. Our findings suggest a complex influence of flavour and other tobacco additives on smokers, and how changes in one or more can lead to a cascade of compensatory and adaptive behaviours by smokers who influence exposure to toxicants. For example, glycerin is commonly added to flavoured WP tobacco because of its humectant, sweetening and preservative properties. ${ }^{34-36}$ It is also added to flavoured WP tobacco to increase smoke production since glycerin produces mist when heated. ${ }^{37}$ This was perhaps reflected in our study participants reporting greater smoke production following smoking the flavoured WP tobacco compared with non-flavoured. This indicates the need for a more comprehensive assessment of the effects of tobacco constituents and additives, specifically on the use of humectants and its effect on smoking behaviour and toxicant exposure. This is also in line with recent policy guidance released by the FDA. The guidance highlighted remaining issues that need to be addressed before updating regulations for WP tobacco products, which include how WP might be used in the absence of flavours. ${ }^{38}$ While providing strong evidence on the potential of flavour limitation on users' experience, our study results also can frame the parameters of future studies needed by the FDA to regulate flavoured WP tobacco. These can include comparing multiple tobacco compositions in terms of flavours, and humectant contents (eg, high glycerin vs low glycerin). Such comparisons will lead to a better understanding of how flavouring and other additives are shaping the overall WP smoking experiences and exposures.
What this paper adds

- Flavoured tobacco has a substantial effect on enhancing the waterpipe (WP) smoking expierence.

- This study demonstrates that flavoured WP tobacco smoking is associated with enhanced subjective smoking experiences, and lower harm perception compared with non-flavoured WP tobacco.

- Eliminating one component of the tobacco (flavour) will lead to a cascade of compensatory and adaptive behaviours by smokers who influence exposure to toxicants.

Key messages

What is the key question?

- What is the main impact of flavour manipulation on waterpipe (WP) smokers' behaviour, toxicant exposure and subjective experiences?

What is the bottom line?

- Despite the clear association between flavour and enhanced subjective experiences, smoking flavoured tobacco was not associated with higher exposure to toxicants compared with non-flavoured tobacco.

Why read on?

- This study provides critical information for regulatory actions regarding the substantial effects of eliminating tobacco flavour on the overall smoking experiences among young adult WP smokers.

Acknowledgements Some of the early findings of this study were previously presented as pilot data at the SRNT 25th Annual Meeting.

Contributors ZBT and WM conceptualised and designed the study, drafted and revised the manuscript, guided and interpreted the analysis. TE, MEK, DB, MV and $A B$ contributed to the acquisition and interpretation of the data, critically revised the article for important intellectual content.

Funding This study was funded by National Institutes of Health $(\mathrm{NIH})$ and the Center for Tobacco Products (CTP) of the the U.S. Food and Drug Administration (FDA) under award R01DA042477. TE is supported by the NIH under Award U54DA036105 and the FDA CTP. The content is solely the responsibility of the authors and does not necessarily represent the views of the NIH or the FDA. TE is a paid consultant in litigation against the tobacco industry and is named on a patent for a device that measures the puffing behaviour of electronic cigarette users.

Competing interests None declared.

Patient consent for publication Not required.

Ethics approval This study was approved by the Florida International University Institutional Review Board.

Provenance and peer review Not commissioned; externally peer reviewed. Data availability statement Data are available upon reasonable request.

\section{ORCID iDs}

Ziyad Ben Taleb http://orcid.org/0000-0001-6894-5535

Mohammad Ebrahimi Kalan http://orcid.org/0000-0001-7709-5392

\section{REFERENCES}

1 Maziak W, Taleb ZB, Bahelah R, et al. The global epidemiology of waterpipe smoking. Tob Control 2015;24(Suppl 1):i3-12.

2 Wang TW, Gentzke A, Sharapova S, et al. Tobacco product use among middle and high school students — United States, 2011-2017. MMWR Morb Mortal Wkly Rep 2018;67:629-33.

3 Kasza KA, Ambrose BK, Conway KP, et al. Tobacco-product use by adults and youths in the United States in 2013 and 2014. N Engl J Med 2017;376:342-53.

4 American College Health Association. American College health Association-National College health assessment II: reference group executive summary spring 2018. 
Silver Spring, MD: American College Health Association, 2018. https://www. acha.org/documents/ncha/NCHA-II_Spring_2018_Reference_Group_Executive_ Summary.pdf

5 Waziry R, Jawad M, Ballout RA, et al. The effects of waterpipe tobacco smoking on health outcomes: an updated systematic review and meta-analysis. Int J Epidemiol 2017:46:32-43.

6 Bahelah R, DiFranza JR, Fouad FM, et al. Early symptoms of nicotine dependence among adolescent waterpipe smokers. Tob Control 2016;25:e127-34.

7 Soneji S, Sargent JD, Tanski SE, et al. Associations between initial water pipe tobacco smoking and snus use and subsequent cigarette smoking: results from a longitudinal study of US adolescents and young adults. JAMA Pediatr 2015;169:129-36.

8 Ben Taleb Z, Laestadius LI, Asfar T, et al. \#Hookahlife: The Rise of Waterpipe Promotion on Instagram. Health Educ Behav 2019;46:106-13.

9 Asfar T, Ben Taleb Z, Osibogun 0, et al. How do waterpipe smoking establishments attract smokers? implications for policy. Subst Use Misuse 2019;54:560-71.

10 Villanti AC, Johnson AL, Ambrose BK, et al. Flavored tobacco product use in youth and adults: findings from the first wave of the PATH study (2013-2014). Am J Prev Med 2017;53:139-51.

11 Hadidi KA, Mohammed FI. Nicotine content in tobacco used in hubble-bubble smoking. Saudi Med J 2004;25:912-7.

12 WHO Study Group on Tobacco Product Regulation. Advisory note: waterpipe tobacco smoking: health effects, research needs and recommended actions by regulators, 2015. Available: https://www.who.int/tobacco/global_interaction/tobreg/Waterpipe\% 20recommendation_Final.pdf [Accessed 10 Oct 2018].

13 Food and Drug Administration, HHS. Deeming tobacco products to be subject to the federal food, drug, and cosmetic act, as amended by the family smoking prevention and tobacco control act; restrictions on the sale and distribution of tobacco products and required warning statements for tobacco products. final rule. Fed Regist 2016;81:28973-9106.

14 Leavens EL, Driskill LM, Molina N, et al. Comparison of a preferred versus nonpreferred waterpipe tobacco flavour: subjective experience, smoking behaviour and toxicant exposure. Tob Control 2018;27:319-24.

15 Ben Taleb Z, Breland A, Bahelah R, et al. Flavored versus nonflavored waterpipe tobacco: a comparison of toxicant exposure, puff topography, subjective experiences, and harm perceptions. Nicotine Tob Res 2019;21:1213-9.

16 Maziak W, Rastam S, Shihadeh AL, et al. Nicotine exposure in daily waterpipe smokers and its relation to puff topography. Addict Behav 2011;36:397-9.

17 Blank MD, Cobb CO, Kilgalen B, et al. Acute effects of waterpipe tobacco smoking: a double-blind, placebo-control study. Drug Alcohol Depend 2011;116:102-9.

18 Maziak W, Ben Taleb Z, Jawad M, et al. Consensus statement on assessment of waterpipe smoking in epidemiological studies. Tob Control 2017;26:338-43.

19 Jacob P, Wu S, Yu L, et al. Simultaneous determination of mecamylamine, nicotine, and cotinine in plasma by gas chromatography-mass spectrometry. J Pharm Biomed Anal 2000;23:653-61.
20 Rose JE, Behm FM, Westman EC, et al. Dissociating nicotine and nonnicotine components of cigarette smoking. Pharmacol Biochem Behav 2000;67:71-81.

21 Malson JL, Pickworth WB. Bidis-hand-rolled, Indian cigarettes: effects on physiological, biochemical and subjective measures. Pharmacol Biochem Behav 2002;72:443-7.

22 Pickworth WB, Moolchan ET, Berlin I, et al. Sensory and physiologic effects of menthol and nonmenthol cigarettes with differing nicotine delivery. Pharmacol Biochem Behav 2002;71:55-61.

23 Popova L, Ling PM. Perceptions of relative risk of snus and cigarettes among US smokers. Am J Public Health 2013;103:e21-3.

24 Hughes JR, Hatsukami D. Signs and symptoms of tobacco withdrawal. Arch Gen Psychiatry 1986;43:289-94.

25 Maziak W, Rastam S, Ibrahim I, et al. CO exposure, puff topography, and subjective effects in waterpipe tobacco smokers. Nicotine Tob Res 2009;11:806-11.

26 Cox LS, Tiffany ST, Christen AG. Evaluation of the brief questionnaire of smoking urges (QSU-brief) in laboratory and clinical settings. Nicotine Tobacco Res. 2001;3:7-16.

27 Vansickel AR, Shihadeh A, Eissenberg T. Waterpipe tobacco products: nicotine labelling versus nicotine delivery. Tob Control 2012;21:377-9.

28 Huynh H, Feldt LS. Estimation of the box correction for degrees of freedom from sample data in randomized block and split-plot designs. J Educ Behav Stat 1976;1:69-82.

29 IBM Corp. IBM SPSS statistics for windows, version 21.0. released, 2012.

30 Brinkman MC. The effect of Humectant and Flavorant content on harmful and potentially harmful constituent emissions in mainstream waterpipe tobacco smoke. Society for research on nicotine and tobacco annual meeting, 2018.

31 Eissenberg T. Tobacco smoking using a waterpipe (Hookah): what you need to know. Aana J 2013;81:308-13.

32 Rappard Jvon, Schönenberger M, Bärlocher L. Carbon monoxide poisoning following use of a water pipe/hookah. Deutsches Aerzteblatt Online 2014;111.

33 Ramôa CP, Shihadeh A, Salman R, et al. Group waterpipe tobacco smoking increases smoke toxicant concentration. Nicotine Tob Res 2016;18:770-6.

34 Lesser MA. Glycerin—Man's most versatile chemical servant. J Chem Educ 1949;26:327.

35 Mah S-K, Leo CP, Wu TY, et al. A feasibility investigation on ultrafiltration of palm oil and oleic acid removal from glycerin solutions: flux decline, fouling pattern, rejection and membrane characterizations. J Memb Sci 2012;389:245-56.

36 RIVM. Tobacco additives: information for professionals, 2012. Available: https://www. rivm.nl/tobacco-additives-information-for-professionals [Accessed 2 Jul 2019].

37 Kienhuis AS, Soeteman-Hernandez LG, Bos PMJ, et al. Potential harmful health effects of inhaling nicotine-free shisha-pen vapor: a chemical risk assessment of the main components propylene glycol and glycerol. Tob Induc Dis 2015;13:15.

38 Food and Drug Administration. Modifications to compliance policy for certain deemed tobacco products, 2019. Available: https://www.fda.gov/media/121384/download [Accessed 12 May 2019]. 